\title{
Synthesis and Characterization of Magnetic Nanostructured Lipid Carriers (mNLCs) for Drug Delivery
}

\author{
Naseem Akhtar ${ }^{1}$, Yin Yin Teo ${ }^{2}$, Mansoor Ani Najeeb ${ }^{3}$, Zubair Ahmad ${ }^{4, *}$ Zarbad Shah $^{1}$ and \\ Md Anwarul Hasan ${ }^{5, *}$ \\ ${ }^{1}$ Department of Chemistry, Bacha Khan University Charsadda, Pakistan \\ ${ }^{2}$ Department of Chemistry, Faculty of Science, University of Malaya, Kuala Lumpur 50603, Malaysia \\ ${ }^{3}$ Department of Chemistry, Haverford College, 370 Lancaster Avenue, Haverford, PA, 19041, USA \\ ${ }^{4}$ Centre for Advanced Materials (CAM), Qatar University, 2713, Doha, Qatar \\ ${ }^{5}$ Department of Mechanical and Industrial Engineering, Qatar University, 2713, Doha, Qatar \\ *E-mail: zubairtarar@qu.edu.qa (Zubair Ahmad) and_ahasan@qu.edu.qa (Md Anwarul Hasan)
}

doi: $10.20964 / 2018.12 .02$

Received: 26 June 2018 / Accepted: 19 September 2018 / Published: 5 November 2018

\begin{abstract}
Magnetic nanoparticles (MNPs) are a class of nanoparticles, which can be manipulated using magnetic fields. Currently, MNPs are recognized as one of the most important mode as a drug carrier while they can also be potentially used as carriers for gene delivery. In this article, magnetic nanostructured lipid carriers (mNLCs) are prepared through co-precipitation method. The particle size and zeta potential, structure and thermal properties of the MNPS have been studied. The produced MNPs were also hydrophobically modified with a long chain of fatty acid namely lauric acid. These modified MNPs were mixed with nanostructured lipid carriers (NLCs) to form mNLCs. The heat capacity and flow of mNLCs was profligate in the presence of a magnetic field which is a worthy attribute for targeted drug delivery applications.
\end{abstract}

Keywords: Magnetic nanoparticles (MNPs), magnetic nanostructured lipid carriers (mNLCs), drug delivery.

\section{FULL TEXT}

(C) 2018 The Authors. Published by ESG (www.electrochemsci.org). This article is an open access article distributed under the terms and conditions of the Creative Commons Attribution license (http://creativecommons.org/licenses/by/4.0/). 